\title{
O BRINCAR E A EXPERIÊNCIA ANALİTICA
}

Sérgio de Gouvêa Franco

Psicanalista,
membro do
Departamento
de Psicanálise do
Instituto Sedes
Sapientiae de São
Paulo; professor
doutor do Curso
de Psicologia da
Universidade
Paulista; membro
pesquisador do
Laboratório de
Psicopatologia
Fundamental da
PUC-SP
RESUMO: O artigo investiga a noção do brincar no pensamento do psicanalista inglês Donald W. Winnicott no contexto amplo de sua obra e principais conceitos. O texto aborda a noção de transicionalidade, a noção de espaço potencial e a noção de tempo. O relacionamento mãe-bebê é estudado e o jogo que aí se dá torna-se referência para o pensamento sobre a clínica e sobre a própria prática clínica. $\mathrm{O}$ artigo oferece uma contribuição à compreensão da novidade epistemológica do pensamento de Winnicott, comparando-o a outros momentos do pensamento científico atual. Mostra como a sessão analítica winnicottiana é viva e alegre, visa a integração e espontaneidade do self e carrega uma radical visão do que seja a psicopatologia humana.

Palavras-chave: Winnicott, o brincar, sessão analítica, epistemologia.

ABSTRACT: Playing and the analytical experience. The article analyses the notion of playing in the thought of the English psychoanalyst Donald W. Winnicott, in the broad context of his work and main concepts such as the notion of transitionality, the notion of potential space and the notion of time. The relationship between mother and baby is studied and the game that arises in this relation becomes a reference for the thought about clinics and for the clinics itself. The article contributes to the understanding of the epistemological novelty of Winnicott's thought, comparing it to other current expressions of the scientific thought. The article also demonstrates how Winnicott's analytical session is lively and joyful, aiming at the integration and spontaneity of the self, conveying a radical vision of what human psychopathology is.

Keywords: Winnicott, playing, analytical session, epistemology. 


\section{INTRODUÇÃO}

Donald Winnicott mudou a noção de sessão analítica quando aproximou a sessão de psicanálise à noção do brincar. Para ele, a sessão se dá mediante a sobreposição de duas áreas do brincar - a do paciente e a do analista. Se o paciente não pode brincar, o trabalho do analista é ajudá-lo a sair desta impossibilidade para a situação do que brinca. Se o analista ele mesmo não pode brincar, neste caso simplesmente não serve para o ofício (WINNICOTT, 1975, p.59). Não podemos encarar o brincar de Winnicott de modo ingênuo; precisamos tirar da noção o que lá está colocado pelo médico inglês. O que pretende Winnicott é ampliar o leque de recursos do analista, e não diminui-lo mediante uma caricatura. Entender o que pensa Winnicott sobre o brincar e a sessão analítica, evocar o enquadre da psicopatologia fundamental, refletir — eis aí o desafio do presente trabalho.

\section{O BRINCAR EM WINNICOTT ${ }^{1}$}

Há uma raiz funda na história da psicanálise que relaciona a brincadeira infantil com a sublimação. A brincadeira se sustenta a partir de uma fantasia que se oculta dentro de si; é tarefa do analista de crianças interpretar esta fantasia. Tal visão talvez tenha tornado a brincadeira em si uma coisa sem importância para a psicanálise. O que propõe Winnicott é algo diferente, ele olha para o brincar em si como um objeto de estudo. Melaine Klein vê a brincadeira como uma forma de comunicação extremamente importante para a sessão com crianças. Winnicott se volta para o brincar, o verbo - não para a brincadeira, um substantivo - como uma coisa a ser olhada em sua potencialidade própria. O brincar como o concebe Winnicott não se limita às crianças apenas, mas se estende aos adultos também.

O brincar de Winnicott em crianças e adultos só pode ser plenamente entendido com a concorrência de sua noção de transicionalidade. Simplificando um pouco, podemos dizer que Freud estabelecera dois campos da experiência dos indivíduos. Por um lado, ele falava na realidade psíquica, desde $A$ interpretação dos sonhos, em que se referia à experiência psíquica, pessoal e interna de cada um. Também falava da realidade externa e compartilhada socialmente, da qual a realidade psíquica se distingue ou até se opõe. Winnicott propõe um campo intermediário, que faz a transição entre os pólos freudianos. Alguns erradamente reduzem este campo intermediário aos objetos que eventualmente o representam - por exemplo, os ursos de pelúcia. Trata-se de fato de uma área intermediária da experiência humana "entre o erotismo oral e a verdadeira relação

\footnotetext{
${ }^{1}$ Examino aqui a noção amadurecida de Winnicott expressa no livro 0 brincar e a realidade, embora seja possível investigar em sua obra anterior o desenvolvimento do conceito.
} 
de objeto" (WINNICOTT, 1975, p.14). Os objetos ditos transicionais são aqueles que não pertencem ao corpo do bebê (não são, por exemplo, o polegar que é chupado) nem são plenamente reconhecidos como a realidade externa compartilhada no social. A transicionalidade está no encontro entre o mundo psíquico e o mundo socialmente construído. Este campo intermediário constituído tanto pela realidade interna quanto pela realidade externa é fundamental para entender o brincar de Winnicott.

Esta área intermediária tem a ver com a crescente capacidade do bebê de perceber e aceitar a realidade socialmente construída. Trata-se de uma transição que começa com a ilusão do bebê, que se percebe como potente e criador do mundo que o circunscreve, passa pela desilusão quanto à sua onipotência e chega a uma certa aceitação da realidade construída pelo social. Na vida adulta esta área intermediária está expressa nas artes, religião e cultura em geral; é o campo também da loucura, quando alguém exige demais da credulidade dos demais. Em crianças e adultos a experiência ilusória não desaparece por completo.

O brincar winnicottiano tem uma topologia e uma temporalidade. O espaço que o brincar ocupa não fica dentro nem tampouco fora da subjetividade, fica na fronteira. O brincar não está no espaço repudiado pelo bebê que constitui o não-eu, nem está inteiramente dentro de sua subjetividade e corpo. Este espaço de brincar Winnicott chamou de espaço potencial e é de início pensado como um espaço que se forma entre a mãe e o bebê.

O modo como Winnicott concebe o brincar tem a ver com vários tempos. No primeiro tempo, o bebê e o objeto estão fundidos. A visão que o bebê tem do objeto é subjetiva. A mãe suficientemente boa se orienta para concretizar aquilo que o bebê está pronto a encontrar. A isto Winnicott chama de criatividade primária, ${ }^{2}$ que só é possível mediante uma ação digamos apaixonada da mãe na direção de seu bebê — uma ação que só aos poucos vai se desfazendo. No segundo tempo, o objeto é repudiado como não-eu, aceito de novo e objetivamente percebido. Neste tempo, a mãe devolve ao bebê o objeto que ele repudiou.

A mãe oscila entre ser o que o bebê tem capacidade de encontrar e ser ela própria, aguardando ser encontrada. Se a mãe tem razoável sucesso no exercício destes papéis, então o bebê tem a experiência mágica da onipotência, o que o prepara para a futura desilusão necessária. Quando a mãe tem uma relação de sintonia inicial com o bebê, estabelece-se um ambiente de confiança e o bebê

\footnotetext{
${ }^{2}$ Conferir o artigo de minha autoria, "Psicopatologia e o viver criativo", apresentado no Laboratório de Psicopatologia Fundamental da PUC-SP, no primeiro semestre de 2002, e que será publicado na Revista Latinoamericana de Psicopatologia Fundamental no ano de 2003.
} 
brinca com a realidade. Trata-se de uma brincadeira muito prazerosa porque neste jogo delicado da subjetividade emergente e dos objetos reais há uma sensação de controle.

Um estádio mais avançado fala da experiência de ficar sozinho na presença de alguém. A criança brinca confiante de que a pessoa a quem ama está lá, disponível, sustentando o brincar. A mãe é esquecida, mas quando lembrada, o é como alguém que merece confiança e pode ser facilmente acessada. Assim, a criança vai ficando pronta para a experiência de desfrutar de uma área de superposição de duas áreas do brincar. Não só o bebê brinca e é observado; a mãe brinca com o bebê também, no começo age de modo a não romper o dinamismo da brincadeira infantil. Depois, a mãe pode introduzir plenamente o seu brincar; a criança, por sua vez, pode experimentar relacionar-se com idéias que não lhe são próprias.

\section{O BRINCAR E A SESSÃO ANALÍTICA}

Esta noção de espaço potencial Winnicott aplica à sessão de análise. O brincar é universal, saudável e de todo desejável, inclusive na sessão de análise. O brincar facilita a comunicação consigo e com os outros, propiciando experiências inéditas de desintegração e integração do paciente. A sessão de psicanálise pode ser pensada como uma manifestação sofisticada e contemporânea da experiência de brincar. A sessão se funda em um espaço e temporalidade próprios que têm semelhanças com o espaço e a temporalidade das relações iniciais mãe-bebê.

A sutileza das relações mãe-bebê deve ser considerada como referência para a sessão analítica. Não se trata de uma visão romântica porque o brincar pode tornar-se assustador. A organização da brincadeira infantil deve ser vista como uma tentativa de prevenir a emergência deste aspecto assustador no brincar. Com freqüência as crianças precisam de alguém que observe o brincar para que o aspecto aterrador não destrua a dimensão criadora da brincadeira. Na sessão também. Esta deve poder sustentar uma experiência criativa do paciente, uma experiência que se desenvolve dentro de certa continuidade do espaço-tempo e que funda uma nova forma de viver como brincar. Como o brincar é uma sutileza - um espaço que fica entre o subjetivo e o objetivo - , sua precariedade deve ser considerada. O analista compreenderá que seu trabalho tem a ver com a sustentação deste brincar do paciente, que se dá em um espaço e tempo construído transferencialmente.

Neste ponto, Winnicott coloca em questão uma interpretação fora do tempo. O setting - visto como um instrumento fundamental do processo analítico - sustenta o brincar que pode levar o paciente à experiência de surpreender-se durante a sessão. Uma interpretação fora de hora pode ser vivida como mera 
inculcação que gera a submissão do paciente. ${ }^{3}$ Muita resistência a uma interpretação extemporânea poderia ser evitada se se considerasse a sessão como uma experiência de superposição do brincar comum analista-paciente.

O verdadeiro brincar infantil — que não é faking ${ }^{4}$ ou um brincar fingido, artificial e desimplicado - aparece com preocupação e compromisso com os elementos da brincadeira. Há uma adesão à brincadeira e uma resistência a sair dela, ainda que a criança não confunda o brincar e o seu poder imaginativo com a realidade socialmente aceita. Na sessão ocorre o mesmo: se não houver uma adesão do paciente e do analista àquele espaço e tempo fora do espaço e tempo comuns, então não há brincadeira. Ambos têm de entrar neste espaço potencial, diferente do espaço-tempo do senso comum. Ambos têm de entrar neste espaço imagético, portador de poder de transformação e brincar. O desafio é brincar com a realidade subjetiva de ambos (paciente e analista) que se presentifica ali mesmo na sessão, de um modo tão concreto que se pode quase tocar. Neste espaço potencial, o interno se torna externo e o tempo antigo e a expectativa do futuro se tornam presentes. Não há mais uma distinção clara entre o que está fora e o que está dentro. Trata-se de um espaço-tempo teatral, onde se vive, cria-se, sofre-se e alegra-se a dupla paciente-analista, numa dramatização que só tem valor se for investida de afeto e sustentada como se esta brincadeira fosse tão real quanto a realidade socialmente construída.

O paciente traz para a sessão-espaço-de-brincadeira elementos de experiências oriundas da realidade socialmente sustentada e os usa como elementos de enriquecimento e transformação no campo transicional, com efeitos no mundo interno. A sessão — sem que haja alucinação — vira um espaço de passagem entre o mundo interno e o mundo externo, com duplo sentido, com potencial de criar ou recriar a transicionalidade infantil. Há interpretação dos fatos exter-

\footnotetext{
${ }^{3}$ Em "Psicopatologia e o viver criativo", procuro destacar como a submissão é um índice de declínio ou falência da experiência criativa. Afirmo ali que uma forma não criativa de lidar com a realidade é a submissão. Ao invés de impregnar o mundo com um olhar e ação próprios, o que pode aparecer é uma experiência de submissão que traz consigo um sentido de inutilidade e uma noção de que nada realmente importa. O viver não criativo manifesta-se neste caso em pessoas firmemente ancoradas na realidade, mas doentes no sentido de que perderam o contato com o mundo subjetivo e com a aproximação criativa dos fatos. A idéia de uma vida submissa é descrita em Winnicott com o auxílio do conceito de um eu com um falso self, com uma falsa personalidade. É uma idéia que tem origem em Freud, quando este destaca que o eu pode estar orientado para o exterior e relacionamentos com o mundo em detrimento do contato com a sexualidade. Winnicott destaca uma sobre-adaptação egóica. O eu está tão aterrorizado com as demandas do id que se afasta de todas as suas excitações; o eu se torna incapaz de incorporar as excitações, que são vividas de modo traumático. Neste sentido, o eu é incapaz de sustentar os riscos envolvidos e as frustrações necessárias no caminho de poder experimentar a satisfação do id.

${ }^{4}$ Palavra inglesa que expressa a idéia daquilo que parece mas não é.
} 
nos e internos e até uma manipulação deles a partir da experiência criada na sessão; pode haver, por exemplo, uma impregnação com sentidos oníricos de experiências ocorridas na realidade social.

Este brincar na sessão certamente envolve o corpo. A excitação está presente. Quando a excitação chega, contudo, a determinado nível, pode afetar a brincadeira e até a integridade do eu do paciente. A sedução do analista, por exemplo, pode ter este efeito desastroso, impedindo o verdadeiro brincar. A excitação deve ser mantida abaixo do ponto em que ela demanda uma gratificação física. Se a excitação sobe e não é gratificada fisicamente, ocorre a frustração, com toda sorte de desorientação que a acompanha. Há a possibilidade, também, de se buscar uma gratificação deslocada, com reações de violência e agressividade. Neste ponto não se pode mais sustentar a sessão, e o brincar atinge seu ponto de saturação. Mas enquanto o brincar ocorre, aparece um elemento legitimamente prazeroso. O brincar é, resumindo, excitante e precário ao mesmo tempo. A excitação e a angústia devem ser mantidas em níveis tais que não destruam pela sua intensidade a possibilidade sempre precária de brincar — uma possibilidade delicada de jogar com os universos todos da experiência do indivíduo.

\section{ESPAÇOS NÃO CONVENCIONAIS}

Winnicott diz de modo explícitona introdução de O brincar e a realidade (WINNICOTT, 1975) que está falando de um paradoxo quanto trata de fenômenos transicionais e espaços potenciais. ${ }^{5}$ Ele apela contra o intelectualismo:

"Minha contribuição é solicitar que o paradoxo seja aceito, tolerado e respeitado, e não que seja resolvido. Pela fuga para o funcionamento em nível puramente intelectual, é possível solucioná-lo, mas o preço disso é a perda do valor do próprio paradoxo." (WINNICOTT, 1975, p.10)

O desrespeito para com o paradoxo pode ser concretizado apegando-se a uma lógica formal clássica, exigindo-se que um objeto esteja dentro ou fora, que o tempo seja o presente ou o passado ou o futuro. Como se não fosse possível pensar com lógicas de outro tipo - é o caso das lógicas inclusivas. O que está em jogo no pensamento de Winnicott é uma temporalidade e uma espacialidade não convencionais. É preciso tolerar o paradoxo que o seu pensamento introduz.

\footnotetext{
${ }^{5}$ Ainda sobre a noção de espacialidade em O brincar e a realidade, conferir os capítulos "A localização da experiência cultural” e "O lugar em que vivemos”, não estudados neste artigo.
} 
Para a lógica clássica, entre o sim e o não, não há uma terceira hipótese. É o chamado princípio do terceiro excluído (algo ou é ou não é). Um forte abalo a este princípio, contudo, tem sido produzido pelas ciências naturais, em particular pela física do século XX. Um exemplo deste abalo foi produzido pela física da luz que assevera que a mesma pode ser entendida como um fenômeno ondulatório e como um fenômeno corpuscular, ao mesmo tempo. Não se pode exigir que a física faça uma opção excludente sobre a natureza da luz: ela seria ondulatória e se propaga de forma contínua, ou a luz é feita de partículas, portanto se propaga de forma discreta? A resposta não pode ser dada aderida ao princípio do terceiro excluído. A luz é ondulatória e corpuscular ao mesmo tempo. Há evidências nas duas direções.

A noção de espaço que Winnicott introduz está imersa em um paradoxo do ponto de vista de uma lógica clássica. Enquanto a realidade psíquica proposta por Freud tem uma localização dentro do corpo, é intrapsíquica, e a realidade externa está localizada nas tramas sociais intersubjetivas, Winnicott quer falar de um espaço que fica entre, um espaço que não pode ser localizado pela lógica do terceiro excluído, segundo a qual ou seria intrapsíquico ou intersubjetivo. O espaço winnicottiano é os dois, esta lá e cá. Winnicott diz claramente que não pretende questionar a noção de espaço interno e espaço externo de Freud. A idéia de Winnicott complementa esta noção, acrescentando este espaço especial que fica fora e dentro ao mesmo tempo, espaço construído pelo bebê e a mãe e recriado na relação analítica.

Freud decerto introduz noções de espacialidade e também de temporalidade que são revolucionárias. A noção de espacialidade aparece, por exemplo, na idéia de níveis mais profundos ou menos profundos na mente humana. Como falar do desejo no sonho e o desejo de dormir senão apelando para a idéia de que estão em níveis diferentes. Para Freud o desejo de dormir está no préconsciente, mais superficial. O desejo, ou pensamento do sonho está no inconsciente, mais profundo. A tópica ajuda a repartir de modo figurado os graus de profundidade do desejo: desde os mais superficiais, mais próximos da consciência, até os mais profundos, que têm origem na infância. É bom lembrar que Freud tomou alguns cuidados para atenuar esta noção de espacialidade, para evitar que ela fosse tomada fisicamente. Foi por isso que valorizou o papel orientado da tópica: para frente e para trás, direção progressiva ou regressiva.

Freud introduz também em sua tópica a noção de tempo. O sonho é um fragmento da vida psíquica infantil. Ele expressa a nostalgia de um estágio do desenvolvimento humano quando o desejo é satisfeito de forma alucinatória. Seu aparelho psíquico, portanto, possui espacialidade, temporalidade e também força e conflito.

Faz parte do pensamento freudiano tratar de um modo novo a relação entre 
o que está dentro - a realidade psíquica - e o que está fora - a realidade social. O aparelho psíquico pensado no ambiente da cultura aparece explicitamente na segunda tópica, mas Freud leva em conta o outro e a cultura desde sempre. A situação transferencial da terapia e a trama edípica, marcos tão fortes dos inícios da psicanálise, não podem ser pensados a partir de um enfoque solipsista nem tampouco nasceram com a segunda tópica. De fato, o pensamento de Freud coloca em cheque exatamente a noção estanque de interior e de exterior da psique tão comum em psicologia. Para ele não há uma condição social estudada pela sociologia e uma condição interna da psique estudada pela psicanálise. O ganho teórico do pensamento freudiano é justo este: falar de uma psique sempre em situação social. A cultura é decisiva no funcionamento da mente humana.

É importante valorizar as noções de espacialidade e temporalidade em Freud. Isto não quer dizer que estas noções não possam ser sofisticadas, apelando-se para recursos que não estavam disponíveis para Freud. A espacialidade winnicottiana vai um pouco além da espacialidade freudiana quando propõe um espaço de objetos que estão dentro e fora ao mesmo tempo. Propõe uma área transicional, na qual aparecem representações que estão no limite entre o interno e o externo, em que há objetos que estão em transição, objetos que estavam dentro e agora estão passando pouco a pouco para fora. Este é o caso da mãe - um objeto em transição para o bebê.

Uma transicionalidade que talvez merecesse ser mencionada aqui é a transicionalidade de que fala a física quântica, porque também obedece a uma lógica não clássica. O conceito quântico pressupõe que só alguns níveis energéticos são possíveis no mundo subatômico, já que a energia chega em pacotes mínimos e portanto salta de um valor para o outro. Quando um elétron muda de nível energético, tudo se passa como se ele desaparecesse de um nível e reaparecesse em um outro. O espaço é portanto descontínuo e o tempo também; na física quântica há uma transição de um nível energético a outro que rompe com a noção clássica de espaço. A lógica envolvida não segue a convencional — trata-se, na verdade, de uma transição com uma espacialidade não convencional como a proposta por Winnicott.

Poderíamos seguir dando exemplos na física contemporânea que nos incentivam a pensar uma espacialidade e temporalidade não convencionais. Os recursos lógicos e matemáticos para um pensamento assim estruturados estão disponíveis. Estaríamos entrando naquilo que o filósofo francês Merleau-Ponty chamou de razão alargada, ou seja, uma razão na qual a racionalidade permitisse e não atrapalhasse pensar o mundo como ele é visto pela ciência atual. ${ }^{6}$ Este

\footnotetext{
${ }^{6}$ Ver o comentário de Marilena Chauí sobre o assunto em CHAUÍ, 1994, p.63.
} 
alargamento nos livra de uma visão que, em nome mesmo da fidelidade à ciência, pode se tornar estreita, autoritária, ideológica, por vezes etnocêntrica. A física vai dando exemplos de como alguns rompimentos epistemológicos cuidadosos são necessários ao avanço da própria ciência. Neste sentido, Freud foi capaz de renunciar os princípios quantitativos de seu Projeto para uma Psicologia Científica de 1895 e introduzir claramente uma explicação psíquica para o funcionamento mental. Destacamos agora os avanços promovidos por Winnicott, que ainda aguardam e merecem estudos e formulações que dêem conta de sua grandeza do ponto de vista da epistemologia e da filosofia da ciência.

Para encerrar esta sessão, lembramos que a noção de espaço introduzida por Winnicott talvez pudesse ser tratada como uma noção de espaço não euclidiano. Nossa noção convencional de espaço está em grande medida baseada no pensamento do matemático grego Euclides, que viveu em torno de 300 a. C. Sua geometria é tal que coincide com nossa experiência com o mundo físico com dimensões de mesma ordem de grandeza que as dimensões de nosso corpo. Muitas experiências da física das partículas ou da cosmologia contrariam, no entanto, a intuição que desenvolvemos no mundo com dimensões parecidas com as de nosso corpo. Nestes espaços imensos ou ínfimos, comparados com o tamanho do nosso corpo, freqüentemente a geometria euclidiana não funciona. Matemáticos de renome vêm desenvolvendo geometrias ditas não euclidianas consistentes - é bom destacar — , que dão conta de fenômenos que não podem ser antecipados pela geometria euclidiana. ${ }^{7}$

Isto tudo para dizer que o paradoxo mencionado por Winnicott não teria o condão de assustar pensadores contemporâneos da ciência, profissionais prontos a se relacionar com espacialidades não euclidianas e temporalidades não convencionais. O espaço potencial de Winnicott poderia talvez ser descrito por uma matemática não euclidiana, que permitisse uma lógica de pertença não excludente: dentro e fora, ao mesmo tempo (Cf. REZENDE e GERBER, 2001).

\section{O BRINCAR E A BUSCA DO SELF}

O brincar é essencial, diz Winnicott, porque é através dele que se manifesta a criatividade (WINNICOTT, 1975, p.80). No espaço potencial, o paciente pode mobilizar todos os recursos disponíveis em sua personalidade. A criação não

\footnotetext{
${ }^{7}$ Um raio de luz seria na física o que mais perto há de uma reta. Considere-se, por exemplo, dois raios de luz ortogonais a um plano. Pela geometria euclidiana, eles não podem se encontrar nunca. Se as indicações são que devido à presença da matéria os raios de luz efetivamente convergem ou divergem, então geometrias elípticas ou hiperbólicas são necessárias. Para citar apenas um nome, menciono o matemático russo Lobatschewsky (1793-1856), que desenvolveu uma geometria hiperbólica inteiramente consistente. De fato, a geometria deste matemático russo tem sido considerada para a descrição de fenômenos astronômicos (COXETER, 1957).
} 
pode ser feita apenas com disciplina; ela se manifesta em um espaço propriamente criativo. A grande obra de criação de que estamos falando, seguindo o pensamento de Winnicott, é o próprio eu — ou self. ${ }^{8}$ Trata-se de um trabalho que se realiza quando se permite um conjunto de brincadeiras, de contrastes, de associações de partes que antes estavam dissociadas. O eu é ao mesmo tempo descoberto e construído - este trabalho só pode ser dar plenamente no ambiente da brincadeira. Quando o ambiente não é o da brincadeira no sentido que Winnicott está propondo, o paciente — adulto e criança — não pode mobilizar seu eu integral. No ambiente criativo e experimentativo da brincadeira é que é possível a manifestação de todas as partes do eu, não apenas do paciente mas do analista também. De outro modo, o que se tem é uma comunicação falsa e artificial, autoritária ou, simplesmente, a comunicação não existe. A verdadeira comunicação se dá neste ambiente de brincadeira, uma comunicação profunda sem ser direta.

Na busca do próprio eu, os pacientes podem estar procurando se encontrar através de seus atos e trabalho. Este tipo de busca - pensa Winnicott - equivale a do bebê que procura construir algo a partir de suas próprias fezes. Tratase de uma busca inútil. Este esforço obsessivo, este tipo de criatividade não serve para encontrar o próprio eu. O self não pode ser encontrado a partir de produções corporais ou mentais, ainda que estas produções possam ter valor. O que se pode dizer é que se qualquer pessoa pretende encontrar o eu a partir de sua produção, trata-se de alguém que já tem um nível rebaixado em sua criatividade. A produção nunca compensa a falta subjacente do sentimento de eu ou self.

Neste caso, o paciente precisa de uma nova experiência — uma experiência de um estado não intencional. O paciente posto na luta por produção e criatividade - sempre orientado por uma intencionalidade - precisa, ao contrário, de um estado de interação livre, de personalidade não integrada. Trata-se de um estado de amorfia. Esta experiência de não-intencionalidade só se dá no ambiente da confiança que um ambiente suficientemente bom propicia. Corpo e mente relaxam na não-intencionalidade. Nesta seção, se permite a liberdade de expressão mesmo que esta se expresse em um fluxo de pensamentos sem ligação. As conexões podem estar sendo feitas onde há ansiedade e defesa. Cabe ao

\footnotetext{
${ }^{8}$ Winnicott sustenta uma distinção entre self e eu. O termo self apresenta-se essencialmente como uma descrição de como o indivíduo se sente do ponto de vista subjetivo. O self aponta para a personalidade total e para a experiência de "sentir-se real". Em termos de desenvolvimento, o self tem sua origem como potencial do recém-nascido; a partir de um ambiente suficientemente bom, desdobra-se um self total, isto é, uma pessoa capaz de estabelecer a distinção entre o eu e o não-eu. Uma distinção importante é a que existe entre um falso self, defensivo, organizado para atender demandas do social, artificial, e um verdadeiro self, de onde surge uma vida espontânea e criativa e as idéias propriamente pessoais.
} 
analista aceitar este fluxo desconexo com naturalidade, sem forçar qualquer conexão artificial, sem tentar encontrar um fio condutor na fala do paciente. Quando o analista tenta encontrar sentido onde não há sentido, de fato ele está perdendo uma oportunidade de acolher seu paciente e deixá-lo experimentar o repouso. O resultado é a desastrosa perda de confiança do paciente. A criatividade de que fala Winnicott, que descobre e cria o eu, nasce de um estado sem demanda por criatividade.

Em resumo, podemos dizer que o relaxamento que nasce de experiências de confiança é a base para a atividade criativa que se manifesta na brincadeira. A soma destas muitas experiências de relaxamento e criação é que permite a formação de um sentimento verdadeiro de self. É no brincar e talvez apenas no brincar que a criança e o adulto experimentam liberdade suficiente para criar e criar-se. É um espaço potencial, ou seja, um espaço onde toda a potência do indivíduo se mobiliza em busca de uma concretização não obsessiva.

\section{A NOÇÃO DE PSICOPATOLOGIA DE WINNICOTT}

Quando Winnicott propõe uma sessão analítica aproximada do brincar, feita em um ambiente de confiança e relaxamento e que visa a descoberta e construção do eu, ele faz isto de um modo que sustenta certa posição sobre a psicopatologia. Estamos diante de uma visão radical que entende que todos estamos imersos na psicopatologia e na saúde ao mesmo tempo: “É importante para nós não encontrarmos clinicamente qualquer linha nítida entre a saúde e o estado esquizóide ou mesmo entre a saúde e a esquizofrenia plenamente desenvolvida” (WINNICOTT, 1975, p.96).

As pessoas que são consideradas pela psiquiatria como doentes podem manifestar índices de saúde: "É possível a uma pessoa esquizóide ou esquizofrênica levar uma vida satisfatória e mesmo realizar um trabalho de valor excepcional” (Idem, 97).

E, por outro lado, pessoas tidas como saudáveis podem estar de fato doentes, profundamente doentes:

"Pode-se afirmar que existem pessoas tão firmemente ancoradas na realidade objetivamente percebida que estão doentes no sentido oposto [ao do esquizóide ou esquizofrênico que possuem um sentido débil da realidade], dada a sua perda do contacto com o mundo subjetivo e com a abordagem criativa dos fatos." (WINNICOTT, 1975, p.97)

\footnotetext{
${ }^{9}$ Conferir sobre este assunto em FERRAZ, 2002.
} 
Quando propõe o acolhimento do paciente em toda a sua patologia, em toda a sua loucura, quando propõe eliminar toda compulsão organizativa da sessão, expressa uma aceitação da condição inescapavelmente pática ${ }^{10}$ da experiência humana. A idéia é que o analista não tenha medo do pático no paciente e em si mesmo. Pelo contrário, há um convite à presentificação do paciente e do analista em toda a sua realidade e experiência, sem restrição, sem qualquer compulsão saneadora. É preciso deixar o estado desintegrado do paciente aparecer e se manifestar. Este acolhimento da loucura de cada um - inclusive a do analista —, da condição psicopatológica fundamental ${ }^{11}$ de cada um, é a condição mesma da relação analítica amadurecida, não invasiva, respeitosa, em que se pode aprender com a doença na linguagem de Berlinck (BERLINCK, 2000, p.7), ou se pode criar a partir da doença, na linguagem de Winnicott.

O que entra em circulação é uma experiência de aprendizado com a loucura e com a morte — dados da experiência de cada um. A negação da loucura só faz produzir uma enorme quantidade de sintomas, que nasce da incapacidade de suportar este lugar de instabilidade e insegurança que é o lugar próprio do humano. Quando se pode aceitar a condição incompleta, não divina, dependente, vulnerável, da experiência humana, pode-se aprender com ela. Para Winnicott, a criatividade vai nascer exatamente da psicopatologia. Nele há uma visão que busca acatar a condição que cria a partir da miséria humana, que funda um mundo e um espaço de vivência relativamente confortáveis, sendo que parte do conforto vem da sensação de desistência de ser o ser total, o ser da completude.

A psicopatologia fundamental tem a ver com a descoberta de que nossa experiência psíquica é sempre sofrida. Tem a ver com a construção de uma visão singular desta dor de cada um, uma singularidade ligada à história do desejo e da frustração do desejo de cada um. Tem a ver com a aceitação criativa, não resignada, não submissa desta experiência de sofrimento e dor; está ligada à

\footnotetext{
${ }^{10}$ Usamos os termos pático e pática neste fim de trabalho de um modo livre, não como devasso ou libertino. A condição pática mencionada refere-se à dor e ao sofrimento psíquico. Trata-se de uma adaptação do grego pathos $(\pi \alpha \theta 0 \sigma)$, de onde vem a palavra em português paixão, patético e, também, patológico. O derivado pathetos $(\pi \alpha \theta \eta \tau \sigma \sigma)$ quer dizer "aquele que tem capacidade de sofrer".

${ }^{11}$ A noção de psicopatologia fundamental tem a ver com a obra do psicanalista francês Pierre Fedida, da Universidade Paris 7, recentemente falecido. No Brasil, o psicanalista Manoel Tosta Berlinck tem se destacado pela difusão desta noção. A expressão se distingue da psicopatologia geral criada por Jaspers, que visa uma objetivação das doenças mentais conhecidas. A psicopatologia fundamental visa resgatar a dimensão propriamente subjetiva e singular do sofrimento humano. Todo humano é atingido por este excesso que a vida traz e o torna um paciente. A experiência de sofrimento pode eventualmente ser transformada em uma experiência criativa e criadora no contanto com o outro.
} 
história de cada um que permite a fundação de si. A análise poderá ser um espaço de experiência e de criação de si, onde se aprende com a própria dor e se aprende a desistir de não sofrer.

\section{CONCLUSÃO}

A experiência com pacientes e consigo mesmo indica que pouco adianta adaptar-se de modo submisso ao mundo socialmente construído e não ter o desfrute de viver. O brincar criativo é um modo de se enfrentar com a realidade que valoriza esta alegria de estar vivo. Frente a um cansaço de sujeição, o brincar com a realidade se apresenta como a possibilidade de criar, de colocar um tom pessoal na experiência, de rearranjar campos. Não apenas desmontar a pretensão narcísica, mas impregnar a realidade com o desejo. A submissão poderá nos transformar em normopáticos na expressão apresentada por Flávio Ferraz, normopáticos marcados por defesas frente às próprias possibilidades e pelo medo que apenas visa a minimização dos riscos. A realidade não será só tema de sujeição mas de criação.

Há uma análise tão protegida por um setting rigoroso que apenas reforça as defesas do analista e do paciente. Há uma segurança tão firme para ambos que impossibilita o acolhimento radical da loucura — uma visão do sofrimento e da patologia humana incongruente com o pensamento e prática clínica de Winnicott. Para ele, o analista se abstém do autoritarismo e da doutrinação e permite uma fruição mesmo desorganizada da sessão. $O$ analista se entrega ao que está acontecendo. A análise é uma experiência para o paciente e para o analista. Se não for possível experimentar este estado de relaxamento, esta condição de aprendizado ativamente passiva, ativamente expectante, de fato não há aprendizado algum: o analista não aprende, o paciente tampouco.

Winnicott relata o tratamento de uma paciente (WINNICOTT, 1975, p.8393), no qual ele permanece freqüentemente em silêncio, não oferece nenhuma interpretação. A recompensa por esta retenção de interpretação é o fato de que a própria paciente faz a interpretação que o analista pensara. Neste caso, o analista trabalha pela não-ação e pela espera, evita qualquer atropelamento do ritmo do paciente. O processo não é apenas ativo, não acontece apenas agindo. A ação, aliás, é marca da vida contemporânea - marca não rara ensandecida. O aprendizado vem também silenciando, deixando passar, permitindo que o paciente se desarranje, se desorganize. O self verdadeiro se constrói aí onde não é tão necessária a defesa. É apenas em um estado não integrado que o criativo pode aparecer, emergir.

A sessão winnicotina é um espaço de desfrute, um espaço lúdico, prazeroso; um espaço partilhado por analista e paciente, que invade o mundo interno de ambos sem que se tenha uma consciência plena do que está ocorrendo. Este 
espaço é curativo por isso, porque o analista não é um objeto externo ao paciente - o que faria pouco impacto sobre ele — , tampouco é um objeto de seu espaço interno - o que seria apenas a experiência com o mesmo.

Brincar e criar são, sobretudo, um modo de o analista se portar diante de seu paciente, esperando que ele mesmo possa brincar e criar com e através de sua patologia, aprender com ela e a partir dela. Neste caso, não há uma recusa da condição pática humana, recusa marcada pelo comportamento defensivo. O analista aceita a patologia, aceita o caos, e espera paciente o brincar criativo. Não busca coerência onde ela não existe, não organiza precipitadamente. A vivência desprotegida da sessão pensada próxima ao brincar promove o encontro do outro e promove o encontro de si mesmo, do self verdadeiro, na expressão winnicottiana.

Recebido em 23/1/2003. Aprovado em 14/4/2003.

\section{REFERÊNCIAS}

ABRAM, J. (2000) A linguagem de Winnicott. Dicionário de palavras e expressões utilizadas por Donald W. Winnicott. Rio de Janeiro: Revinter.

BERLINCK, M. T. (2000) Psicopatologia fundamental. São Paulo: Escuta.

COXETER, H. S. M. (1957) Non-Euclidean Geometry. 3. ed. London: Oxford University Press.

CHAUÍ, M. (1994) Convite à filosofia. São Paulo: Ática.

FEDIDA, P. (1988) Clínica psicanalítica — Estudos. Trad. C. Berliner et al. São Paulo: Escuta.

FERRAZ, F. C. (2002) Normopatia. Clínica psicanalítica. São Paulo, Casa do Psicólogo.

FREUD, S. (1996) Edição standard brasileira das obras psicológicas completas. Comentários e Notas de J. Strachey. Colaboração de A. Freud. Edição brasileira dirigida por J. Salomão. Rio de Janeiro: Imago.

GURFINKEL, D. (2001) Do sonho ao trauma: Psicossoma e adições. São Paulo: Casa do Psicólogo.

LAPLANCHE, J e PONTALIS, T. (1997) Vocabulário da psicanálise. São Paulo: Martins Fontes.

MACEDO, H. O. (1999) Do amor ao pensamento. A psicanálise, a criação da criança e D.W.Winnicott. São Paulo: Leterra.

(2001) Entrevista concedida a M. E. Costa Pereira, Revista Latinoamericana de Psicopatologia Fundamental. São Paulo: Escuta, v. IV, n.4, p.138-147, dezembro.

OUTEIRAL, J. O. e GRANA, R. B. (1991) Donald W. Winnicott: Estudos. Porto Alegre: Artes Médicas. 
REZENDE, A. M. e GERBER, I. (2001) A psicanálise "atual" na interface das "novas" ciências. São Paulo: Via Lettera.

WINNICOTT, D. W. (1975) O brincar \& a realidade. Trad. J. O. A. Abreu e V. Nobre. Rio de Janeiro: Imago.

(1983) O ambiente e os processos de maturação. Estudos sobre a teoria do desenvolvimento emocional. Trad. I. C. S. Ortiz. Porto Alegre: Artmed. . (1990) Natureza humana. Trad. D. L. Bogomoletz. Rio de Janeiro: Imago.

. (1999) Tudo começa em casa. Tradução P. Sandler. São Paulo: Martins Fontes.

(2001) A família e o desenvolvimento individual. Trad. M. B. Cipolla. São Paulo: Martins Fontes.

Sérgio de Gouvêa Franco

Av. Onze de Junho 1.291/42

04041-054 São Paulo SP

Tel (11) 5574-1175 (consultório)

sgfranco@attglobal.net 